\title{
Iron deficiency diagnosed using hepcidin on critical care discharge is an independent risk factor for death and poor quality of life at one year: an observational prospective study on 1161 patients
}

Sigismond Lasocki ${ }^{1 *}$ (D) Thibaud Lefebvre ${ }^{2,3}$, Claire Mayeur $^{4}$, Hervé Puy $^{2,3}$, Alexandre Mebazaa $^{4}$, Etienne Gayat ${ }^{4}$ and on behalf of the FROG-ICU study group

\begin{abstract}
Background: Iron deficiency is difficult to diagnose in critically ill patients, but may be frequent and may impair recovery. Measurement of hepcidin could help in the diagnosis of iron deficiency. We aim to assess if iron deficiency diagnosed using hepcidin is associated with poorer outcome one year after an intensive care unit stay.

Methods: We used the prospective FROG-ICU, multicentre ( $n=28 \mathrm{ICUs})$, observational cohort study of critically ill survivors followed up one year after intensive care unit discharge. Iron deficiency was defined as hepcidin < $20 \mathrm{ng} / \mathrm{l}$, ferritin $<100 \mathrm{ng} / \mathrm{l}$ or soluble transferrin receptor (STfR)/log(ferritin) $>0.8$, measured in blood drawn at intensive care unit discharge. Main outcomes were one-year all-cause mortality and poor quality of life (defined as a Short Form 36 (SF-36) score below the median).

Results: Among the 2087 patients in the FROG-ICU cohort, 1570 were discharged alive and 1161 had a blood sample available at intensive care unit discharge and were included in the analysis. Using hepcidin, 429 (37\%) patients had iron deficiency, compared to 72 (6\%) using ferritin alone and 151 (13\%) using the sTfR/log (ferritin) ratio. Iron deficiency diagnosed according to low hepcidin was an independent predictor of one-year mortality (OR 1.51 (1.10-2.08)) as was high sTfR/log ferritin ratio $(O R=1.95(1.27-3.00))$, but low ferritin was not. Severe ID, defined as hepcidin < $10 \mathrm{ng} / \mathrm{l}$, was also an independent predictor of poor one-year physical recovery (1.58 (1.01-2.49)).

Conclusions: Iron deficiency, diagnosed using hepcidin, is very frequent at intensive care unit discharge and is associated with increased one-year mortality and poorer physical recovery. Whether iron treatment may improve these outcomes remains to be investigated.
\end{abstract}

Keywords: Iron deficiency, Outcome, Critically ill, Quality of life, Hepcidin

\footnotetext{
* Correspondence: sigismond@lasocki.com

1 Département Anesthésie Réanimation, UBL Université, CHU Angers, 4 rue

Larrey, 49933 Angers Cedex 9, France

Full list of author information is available at the end of the article
}

(c) The Author(s). 2018 Open Access This article is distributed under the terms of the Creative Commons Attribution 4.0 International License (http://creativecommons.org/licenses/by/4.0/), which permits unrestricted use, distribution, and reproduction in any medium, provided you give appropriate credit to the original author(s) and the source, provide a link to the Creative Commons license, and indicate if changes were made. The Creative Commons Public Domain Dedication waiver (http://creativecommons.org/publicdomain/zero/1.0/) applies to the data made available in this article, unless otherwise stated. 


\section{Background}

Iron deficiency (ID) is one of the main causes of chronic disease. ID affected more than $10 \%$ of the world's population in 2015 and is responsible for almost half of all anaemia worldwide, which is the first cause of health impairment [1]. ID anaemia is indeed one of the leading causes of years of living with disability $[1,2]$. However, ID is not only responsible for anaemia, it also causes fatigue and muscle weakness, independently of anaemia [3]. This has been notably described in patients with heart failure, for whom ID is associated with impaired cardiac function and increased mortality $[4,5]$. ID may also be important in the prognosis of critically ill patients. First ID is frequent on admission in intensive care units (ICU), affecting $20-40 \%$ of the patients [6-8]. ID on admission has been associated with longer ICU stay, more renal failure or ICU-acquired infections $[6,8]$. Because critically ill patients are exposed to frequent blood sampling and other causes of blood loss (including surgery, extracorporeal circuit, invasive procedures, etc.) $[9,10]$, they are exposed to high iron losses. Daily blood loss in these patients can be as high as $128 \mathrm{ml}$ of blood per day [10], which represents 2-3 times the daily need for erythropoiesis [11]. ID is thus expected to be frequent on ICU discharge and may impair the post-ICU rehabilitation. Unfortunately, ID is difficult to diagnose using conventional markers (i.e. ferritin) in the presence of inflammation. Prevalence of ID on discharge is thus probably underestimated, with observed prevalence of less than $10 \%$ [12]. Many markers have been proposed to diagnose ID in the presence of inflammation $[6-8,13]$. However, there is no consensus and the best markers (i.e. the percentage of hypochromic red cells) [14] are not usable in case of blood transfusion, which is very frequent in critically ill patients. Thus, the remaining proposed marker in this context is the ratio between soluble transferrin receptor and the log (ferritin) (sTfR/log ferritin) [15].

In recent decades, the understanding of iron metabolism has been greatly improved by the discovery of its master regulator, hepcidin [16]. A low hepcidin level may indicate ID in the critically ill patient [11, 17]. Because hepcidin may indicate ID and because ID is responsible for muscular weakness and fatigue, we hypothesised that ID diagnosed according to low plasma hepcidin or high sTfR/log(ferritin) on ICU discharge could predict a poorer outcome and quality of life (QOL) in critically ill patients. We used the prospective Frog-ICU cohort [18, 19] to determine whether ID diagnosis using these markers, measured at ICU discharge, were predictive of one-year mortality and QOL in critically ill patients discharged alive from ICU.

\section{Methods}

We used data from the prospective observational cohort of the French and euRopean Outcome reGistry in Intensive Care Units (FROG-ICU). Briefly, this prospective study has been designed to better understand long-term outcome after ICU discharge and risk factors for morbidity and mortality [19]. Plasma was collected on ICU discharge and patients were followed for one year, with quality of life (QOL) assessment using the Short Form 36 (SF-36) questionnaire. Patients from 28 ICUs (and 19 hospitals in France and Belgium) were included if they were ventilated for more than $24 \mathrm{~h}$ or if they received catecholamine for more than $24 \mathrm{~h}$. Patients were followed up on ICU discharge and at 3, 6 and 12 months after discharge [18]. The Ethical Committees waived the need for written consent; all patients and/or next of kin were informed and oral consent was documented in the patients' medical records by the investigator. We followed the "Strengthening of reporting in observational studies in epidemiology" (STROBE) statement to report the results.

\section{Hepcidin measurement}

Using a previously validated and published mass-spectrometry protocol [20], hepcidin concentration was measured in the blood sample obtained at ICU discharge. Briefly, after plasma pre-treatment by solid phase extraction, hepcidin was quantified using ultra high-pressure chromatography coupled to triple quadripole (Acquity UPLC-Xevo TQMS, Waters Guyancourt, France). Using this method, normal ranges for hepcidin concentration are between 1 and $20 \mathrm{ng} / \mathrm{l}$. However, < $20 \mathrm{ng} / \mathrm{l}$ hepcidin concentration indicates ID in critically ill patients, as it corresponds to the threshold value determined using ELISA [17].

\section{Iron profile}

An iron profile was determined in all patients, by measuring serum ferritin and soluble transferrin receptor (sTfR) using a Vista analyzer and NLatex sTfR, BNPprospec (Siemens, France). Iron deficiency was defined according to the usual definition in the presence of inflammation, by either ferritin $<100 \mathrm{ng} / \mathrm{l}$ or sTfR/log(ferritin) ratio $>0.8[14,15]$.

\section{Statistical analysis}

All results are expressed as median with interquartile range or count with percentage. Marginal associations were tested using the chi-squared test and Mann-Whitney test as appropriate. The primary endpoint was to assess whether low hepcidin (i.e. hepcidin $<20 \mathrm{ng} / \mathrm{l}$, corresponding to ID in the critically ill) predicts poorer outcome, defined as ICU discharge. To account for possible cofounders, we used logistic regression and 
adjusted this analysis according to the principal factors associated with one-year mortality in the Frog-ICU cohort (see [18] for complete description of multivariate analysis): age, gender, diabetes mellitus, liver disease, surgical/medical, septic shock and haemoglobin $(\mathrm{Hb})$ at discharge. We also evaluated the predictive values of the other biological markers of ID, using the standard definitions (i.e. ferritin $<100 \mathrm{ng} / \mathrm{l}$ and $\mathrm{sTfR} / \log ($ ferritin $)>0.8$ ). Odds ratio (OR) and confidence interval (CI) at $95 \%$ was calculated as a measure of association. The log linearity of the quantitative variables was evaluated using restricted cubic splines.

A secondary aim was to evaluate if low hepcidin (i.e. presence of iron deficiency) predicts one-year QOL of these patients. For this purpose, we defined poorer QOL as a SF-36 score lower than the median observed SF-36 scores in our critically ill population, for the two dimensions (i.e. physical and mental). In order to complete our results, we conducted sensitivity analysis, using a lower threshold for ID (severe ID, defined as Hepcidin < $10 \mathrm{ng} / \mathrm{l})$.

Because the diagnosis of ID may be modified in the presence of inflammation, we modelled the probability of one-year mortality according to the ID markers (i.e. hepcidin and sTfR/log(ferritin)) and the level of inflammation, by separating the population according to the different tertiles of interleukin-6 levels at discharge. A $p$ value $<0.05$ was considered statistically significant. All statistical analyses were performed using $\mathrm{R}$ statistical software version 3.1.1 or above (The $\mathrm{R}$ Foundation for Statistical Computing, Vienna, Austria).

\section{Results}

Between August 2011 and June 2013, 2087 patients were included in the FROG-ICU cohort, among them 1570 were discharged alive from the ICU and 1161 had a blood sample available together with one-year follow-up and were thus included in this study (Fig. 1).



\section{ID diagnosis}

Hepcidin measurements were available for 1161 patients, ferritin for 1157 patients and sTfR/ferritin for 1146 patients. According to their hepcidin concentrations, 429 patients (37\%) had ID (i.e. hepcidin < $20 \mathrm{ng} / \mathrm{l}$ ) at ICU discharge. Based on ferritin, only $72(6 \%)$ patients could be considered as having ID (i.e. ferritin < $100 \mathrm{ng} / \mathrm{l}$ ). Based on the sTfR/log(ferritin) ratio, 151 (13\%) patients had ID (i.e. $s T f R / \log ($ ferritin $)>0.8$ ). Interestingly the concordance on ID diagnosis between hepcidin and ferritin was not so low $(67 \%, 95 \%$ CI $65-70 \%)$ but was better with sTfR/(log ferritin) (71\%, 95\% CI 68-73\%, Fig. 2). However, hepcidin identified more patients with ID (Fig. 2).

In our study population, hepcidin values were not correlated to $\mathrm{Hb}$ values, but there was positive correlation with CRP (and IL-6) and ferritin, and negative correlation with sTfR (Additional file 1: Figure S1). Patients with ID identified by hepcidin on (i.e. hepcidin $<20 \mathrm{ng} /$ l) were more often women, had more liver disease and lower $\mathrm{Hb}$ at discharge, but their renal function was better than patients without ID. Patients with ID at ICU discharge had received fewer transfusion during their ICU stay (Table 1).

\section{ID and outcome}

ID diagnosed by hepcidin was associated with one-year mortality (Table 1). ID diagnosed by $\mathrm{sTfR} / \log$ (ferritin) ratio $>0.8$, was also associated with higher mortality (17.7\% vs $27.8 \%, p=0.003)$, but ID defined by low ferritin (i.e. < $100 \mathrm{ng} / \mathrm{l})$ was not $(18.1 \%$ compared to $19.2 \%$ mortality, respectively, in patients with "low" and "high" ferritin, $p=0.93$ ).

The multivariate analysis adjusted for the main confounding factors confirmed that ID diagnosed by hepcidin is an independent predictor of one-year mortality as well as high sTfR/log ferritin ratio (Table 2 and Fig. 3). All the odds ratios from the multivariate analysis for the different definitions of ID are reported in Additional file 2: Table S1. Figure 4 shows the Kaplan-Meier survival curves of patients with and without ID, showing higher mortality in those with ID (hazard ratio $(\mathrm{HR})=1.41$ $(1.10-1.89), p=0.01)$. These associations persisted when patients were separated according to their levels of inflammation (according to IL-6) (Additional file 3: Figure S2). The shape of the observed curves could indicate that a different threshold may be appropriate in the presence of inflammation (i.e. around $40-50 \mathrm{ng} / \mathrm{ml}$ for hepdicin) or in low inflammation (i.e. $>0.6$ for the sTfR/ $\log ($ ferritin) ratio (see Additional file 3: Figure S2)). In addition, severe ID defined as hepcidin $<10 \mathrm{ng} / \mathrm{l}$ was also independently associated with a poor physical QOL at one year, while the other ID markers were not (Fig. 3). 

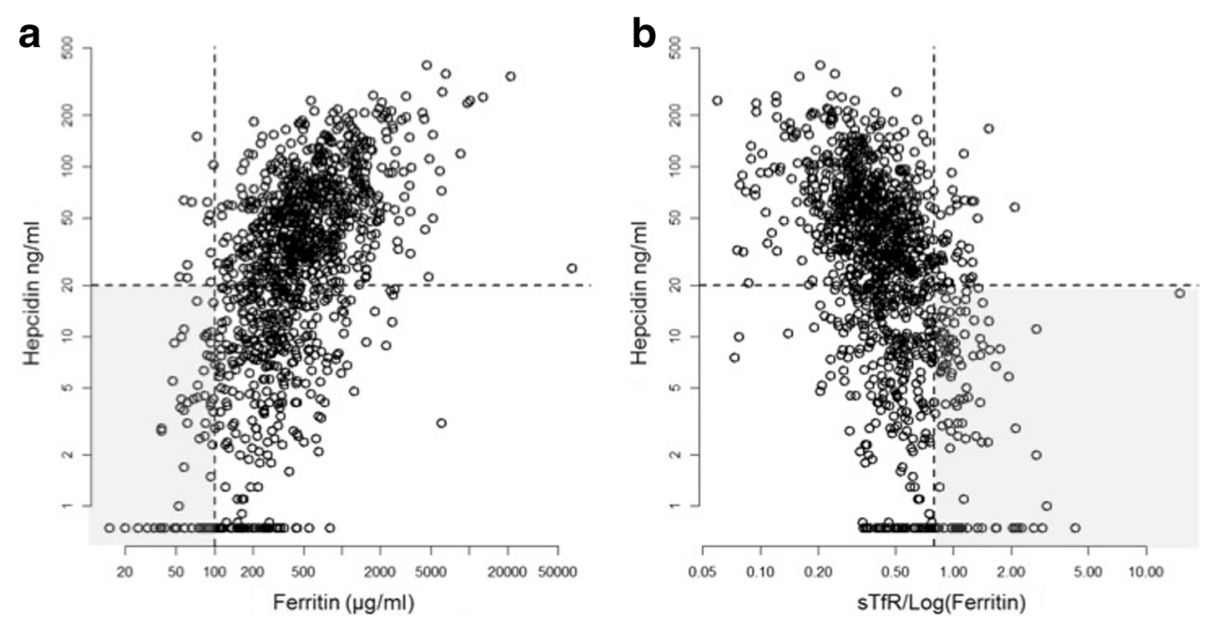

Fig. 2 Relationship between hepcidin and ferritin (a) or soluble transferrin receptor (sTfR)/log(ferritin) (b). We identified positive correlation between log(hepcidin) and ferritin (a) (Pearson's correlation coefficient [95\% Cl], 0.59 [0.55-0.62]) and negative correlation with sTfR/log(ferritin) (b). The concordance for iron deficiency (ID) diagnosis according to hepcidin and ferritin (a) was 67\%, 95\% Cl 65-70\% (i.e. the proportion of patients with hepcidin $<20 \mathrm{ng} / \mathrm{l}$ and ferritin $<100 \mathrm{ng} / \mathrm{l}$ or hepcidin $>20 \mathrm{ng} / \mathrm{l}$ and ferritin > 100 ng/l) and for sTfR/log(ferritin) (b) it was $71 \%, 95 \%$ $\mathrm{Cl}$ 68-73\%. Grey areas indicate the concordance between the different markers. Lower right (a) and left (b) panels indicate ID according to hepcidin that was not diagnosed according to ferritin (a) or sTfR/log(ferritin) (b). CRP, C-reactive protein

\section{Discussion}

In this prospective cohort of critically ill patients we observed that ID diagnosed by low hepcidin or high sTfR/ $\log$ ferritin ratio is frequent at ICU discharge, affecting almost $40 \%$ of the patients and that ID is an independent predictor of one-year mortality. In addition, severe ID defined by hepcidin $<10 \mathrm{ng} / \mathrm{l}$ was also an independent predictor of one-year poor physical QOL.

This relatively high prevalence of ID is consistent with the prevalence observed in the general population (around $30-40 \%$ in menstruating women or preschool children) [21,22] or in populations of patients such as those in the perioperative period (prevalence between 35 and $70 \%$ ) [23] or patients with cardiac disease (prevalence around 40-50\%) [24]. However, there are very few data available in critically ill patients, especially at ICU discharge. On admission to ICU, the prevalence of ID varies from $9 \%$ to almost $40 \%[6,8,17,25-27]$. These variations in ID prevalence are mainly related to the biological test that is used to diagnose ID. In the general population, ferritin is the gold standard for ID diagnosis [22]. However, ferritin synthesis is induced by inflammation, decreasing its interest as a diagnostic tool of ID in such conditions. Inflammation is present in virtually all critically ill patients and this probably explains why the prevalence of ID, diagnosed by low ferritin (i.e. ferritin < $100 \mu \mathrm{g} / \mathrm{l})$ is $<10 \%$ on admission to ICU [27] or at discharge [12]. This is why other markers are proposed to diagnose ID in the presence of inflammation. Red blood cell indices, such as the percentage of hypochromic red cells or reticulocyte haemoglobin content are considered to be the best variables available to diagnose ID in the presence of inflammation [14]. Unfortunately, these parameters cannot be used to diagnose ID when patients receive blood transfusions, which is often the case in critically patients. sTfR and its ratio to $\log$ (ferritin) has been proposed to diagnose ID in the presence of inflammation $[14,15]$. In this cohort, ID defined by a low sTfR/log(ferritin) ratio makes it possible to diagnose ID in an important number of critically ill patients discharged from ICU and these patients had a poor outcome. However, this assay has some limitations, it is quite expensive and is not standardized [14]. The reproducibility of measures remains uncertain. Hepcidin quantification appears promising and a number of laboratories are collaborating towards global harmonization of hepcidin assays [28]. The prevalence of ID identified by hepcidin that we observed in this cohort is consistent with the expected; as the prevalence of ID on admission is around $30-40 \%$, the prevalence of ID on discharge is expected to be the same or higher due to frequent blood loss (even if ID on admission may be also associated with higher mortality). Because hepcidin is higher in patients who have received blood transfusions [29] and because around $40 \%$ of the patients have been transfused, it is possible that more patients had ID. In addition, hepcidin synthesis is linked to the iron stores and to the level of inflammation [11, 29, 30]. Hepcidin could also be useful to indicate when iron treatment could be necessary, in fact elevated hepcidin prevents the mobilization of iron from stores, by blocking the ferroportin, whereas low hepcidin allows the expression of ferroportin at the cell membrane of macrophages and thus the export of iron from stores $[11,30]$. 
Table 1 Patients characteristics according to the diagnosis of ID (i.e. hepcidin $<20 \mathrm{ng} /$ )

\begin{tabular}{|c|c|c|c|}
\hline & Non-ID $(n=732)($ hepcidin $\geq 20$ ng/l) & ID $(n=429)($ hepcidin < 20 ng/l) & $p$ \\
\hline Age (years) & 61 (50 to 72) & 59 (47 to 72 ) & 0.25 \\
\hline Women & $240(32.8)$ & $183(42.7)$ & 0.00081 \\
\hline Charlson's score & $3(1$ to 4$)$ & $3(1$ to 4$)$ & 0.32 \\
\hline Diabetes mellitus & $112(15.3)$ & 89 (20.7) & 0.02 \\
\hline Chronic heart failure & $41(5.6)$ & $34(7.9)$ & 0.14 \\
\hline Hypertension & $268(36.6)$ & $185(43.1)$ & 0.029 \\
\hline Liver disease & $31(4.2)$ & $44(10.3)$ & $<0.001$ \\
\hline Cancer & $98(13.4)$ & $43(10)$ & 0.094 \\
\hline \multicolumn{4}{|l|}{ ICU admission } \\
\hline SAPS $\|$ & 46 (34.5 to 59$)$ & 46 (34 to 59$)$ & 0.87 \\
\hline SOFA & 6 (4 to 9 ) & 6 (4 to 9) & 0.71 \\
\hline Septic shock & $172(23.5)$ & $78(18.2)$ & 0.038 \\
\hline eGFR (ml/min) & 82 (40.4 to 106$)$ & 87.9 (56.2 to 109$)$ & 0.0044 \\
\hline $\mathrm{Hb}(\mathrm{g} / \mathrm{dl})$ & 10.2 (9 to 11.6$)$ & $9.9(9.1$ to 11.1$)$ & 0.032 \\
\hline \multicolumn{4}{|l|}{ ICU stay } \\
\hline ICU LOS (days) & 13 (7 to 22$)$ & 12 (7 to 20$)$ & 0.19 \\
\hline Renal support $n(\%)$ & $140(19.1)$ & $64(14.9)$ & 0.079 \\
\hline Catecholamine $n(\%)$ & $547(74.7)$ & $294(68.5)$ & 0.025 \\
\hline Transfusion $n(\%)$ & $343(46.9)$ & $162(37.8)$ & 0.0027 \\
\hline \multicolumn{4}{|l|}{ ICU discharge } \\
\hline $\mathrm{Hb}(\mathrm{g} / \mathrm{dl})$ & 10.1 (9 to 11.3) & 9.8 (8.9 to 10.8$)$ & 0.011 \\
\hline CRP (mg/l) & $69.4(32.2$ to 117.3$)$ & 33 (13.9 to 66.7) & $<0.001$ \\
\hline Ferritin $(\mu \mathrm{g} / \mathrm{l})$ & 543.5 (339.8 to 932.2) & 240 (138 to 366) & $<0.001$ \\
\hline sTfR (mg/l) & 1 (0.8 to 1.4$)$ & $1.4(1$ to 1.9$)$ & $<0.001$ \\
\hline sTfR/log ferritin & 0.37 (0.28 to 0.51$)$ & 0.57 (0.43 to 0.85$)$ & $<0.001$ \\
\hline IL-6 (ng/l) & 37.1 (19.6 to 70$)$ & 19.8 (9.4 to 38.4$)$ & $<0.001$ \\
\hline \multicolumn{4}{|l|}{ Outcome at one year } \\
\hline - global score & 56.9 (35.9 to 76.6$)$ & 53.6 (34.3 to 73.7) & 0.21 \\
\hline - Mental QOL (MCS) & 58.8 (36.9 to 77.9$)$ & 57.9 (35.9 to 77 ) & 0.44 \\
\hline - Physical QOL (PCS) & 54.7 (33.6 to 78.8$)$ & 50 (31.2 to 72.7$)$ & 0.11 \\
\hline One-year mortality & $123(16.8)$ & $99(23.1)$ & 0.011 \\
\hline
\end{tabular}

Data are expressed as median (Q1-Q3) or number (percentage)

ID iron deficiency, ICU intensive care unit, SAPS // Simplified Acute Physiology Score, SOFA sequential organ failure assessment, eGFR estimated glomerular filtration rate, $H b$ haemoglobin, $L O S$ length of stay, CRP C-reactive protein, sTfR soluble transferrin receptor, IL-6 interleukin 6, QOL quality of life

Table 2 Result of the multivariate model for the prediction of one-year post-ICU mortality

\begin{tabular}{lll}
\hline & OR $[95 \% \mathrm{Cl}]$ & $P$ value \\
\hline Female gender & $0.78[0.56 ; 1.09]$ & 0.14 \\
Septic shock & $1.27[0.89 ; 1.81]$ & 0.18 \\
Diabetes mellitus & $1.50[1.04 ; 2.16]$ & 0.03 \\
Age (per year) & $1.05[1.04 ; 1.06]$ & $<0.001$ \\
ID (hepcidin <20 ng/l) & $1.51[1.10 ; 2.08]$ & 0.01 \\
Chronic liver disease & $2.51[1.45 ; 4.33]$ & $<0.001$ \\
\hline
\end{tabular}

All the variables retained in the final model of the princeps publication were added to this model [18]

$O R$ odds ratio, $\mathrm{Cl}$ confidence interval, ID iron deficiency
In this cohort, we observed that severe ID is associated with both increased one-year mortality and poorer physical QOL. This is also consistent with observations that ID is a risk factor for mortality and morbidity in patients with cardiac disease [4]. Indeed, ID has been shown to be responsible for decreased mitochondrial complex I activity, decreased exercise capacity and left ventricular ejection fraction in an animal model [31]. ID has been also associated with decreased muscular function (skeletal and myocardial) and this may explain the usual association reported between ID and fatigue [3, 12, 32]. 


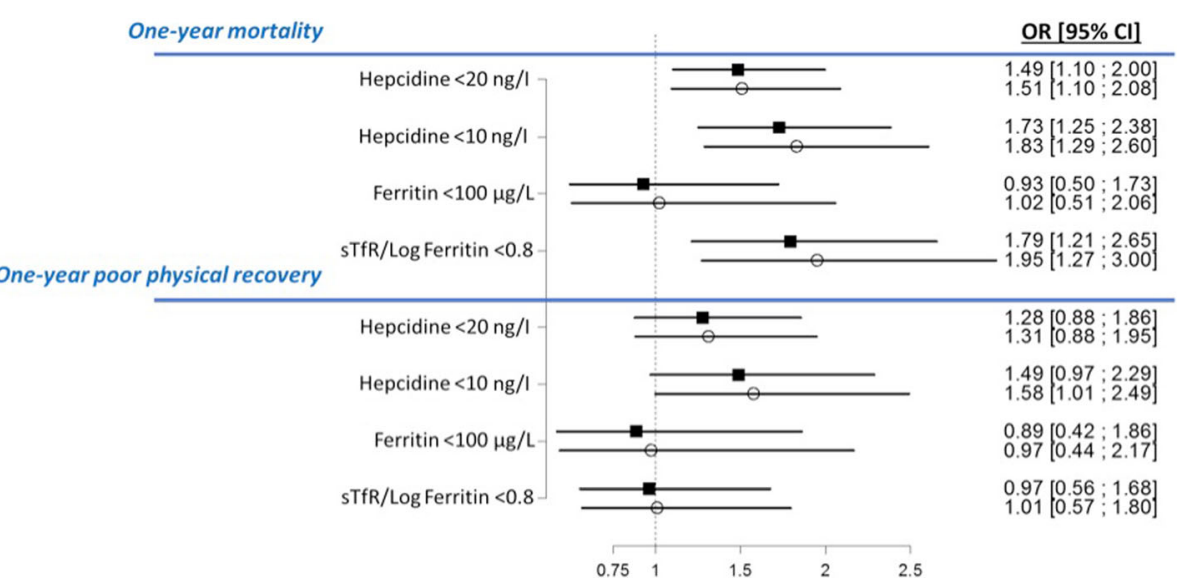

Fig. 3 Odd ratio for one-year mortality and poor physical quality of life according to the different markers of iron deficiency. Squares indicate crude odd ratios and open circles indicate adjusted OR for main cofounding factors (age, gender, diabetes mellitus, liver disease, surgical/medical admission, septic shock and haemoglobin at discharge ). Poor physical recovery was defined as a physical component of the Short Form 36 score below the median value (i.e. 53) at one year. The SF-36 was available in 466 patients at one year. OR, odds ratio; 95\% Cl, 95\% confidence interval, sTfR, soluble transferrin receptor

Our study has some limitations. We used different definitions of ID, but we could also have used other markers such as erythrocyte zinc protoporphyrin [7, 25]. However, this marker may be influenced by blood transfusion and may not be suitable in these patients (at least at the end of their stay, with a transfusion rate around $40 \%$ ). We observed an association between low hepcidin and liver disease, but we do not have enough data to further investigate this association. Although the association



between ID and poor outcomes is supported by a physiological rationale, our data do not demonstrate that iron treatment is beneficial in these critically ill patients. Furthermore, we do not have blood samples after ICU discharge to determine whether some patients did recover from ID or not and if ID at 3, 6 or 12 months is still associated with poor outcomes. We also do not know if some of these patients have been treated with iron after ICU discharge, but this is not likely since iron is rarely proposed in these patients. We also could have investigated the link between high hepcidin and the outcomes. Indeed, we observed that high hepcidin was also associated with higher mortality (as shown in Additonal file 3: Figure S2 for the highest tertile), and some authors report that high hepcidin (on admission) is associated with blood transfusion for example [29]. But, although ID is treatable using iron, high hepcidin is not (because anti-hepcidin antibodies are not available yet). It is thus more indicative of more severe inflammation [29].

Interestingly, treatment of ID using intravenous iron has been proven to improve symptoms of fatigue, physical and mental QOL and even cardiac function [33, 34]. To date, iron treatment is not recommended for critically ill patients. However, we have already demonstrated in an animal model of critical care anemia with ID, that iron may be used to treat anemia, without toxicity (neither oxidative stress induction nor increased risk of infection) [35]. Some human data are promising. Intravenous iron does not induce more oxidative stress in critically ill patients compared to healthy volunteers [36], and it has been shown to improve haemoglobin level at hospital discharge [37]. The results of a prospective randomized controlled study (i.e. Hepcidan study, NCT02276690) [38] designed to assess whether diagnosing ID using this mass spectrometry 
hepcidin measurement on ICU discharge could improve the post-ICU rehabilitation of critically ill patients are expected soon and could help clinicians decide how to diagnose ID in the critically ill and whether iron treatment is useful.

\section{Conclusions}

Iron deficiency, diagnosed using hepcidin concentration $(<20 \mathrm{ng} / \mathrm{l})$ or $\mathrm{sTfR} / \log$ (ferritin) ratio $(>0.8)$ at ICU discharge, is associated with increased one-year mortality. Severe ID (hepcidin $<10 \mathrm{ng} / \mathrm{ml}$ ) is also an independent predictor of poor physical QOL at one year.

\section{Additional files}

Additional file 1: Figure S1. Relationship between hepcidin and biological parameters. To better describe the relationship between hepcidin and biological parameters, we drew linear regressions between hepdicin (log transformed) and respectively haemoglobin (A), ferritin (B), C-reactive protein (CRP) (C), and soluble transferrin receptor (sTfR) (D). Pearson's correlation coefficients [95\% Cl] were as follows: (A) 0.08 [0.02-0.14], (B) 0.59 [0.55-0.62], (C) 0.37 [0.32-0.42], (D) -0.37 [ -0.42 to -0.32$]$. (DOCX $389 \mathrm{~kb}$ )

Additional file 2: Table S1. Result of the multivariate model for the prediction of one-year post-ICU mortality according to the different ID definitions. All the variables retained in the final model of the princeps publication were added to this model [18]. OR, odds ratio; Cl, confidence interval; ID, iron deficiency. (DOCX $19 \mathrm{~kb}$ )

Additional file 3: Figure S2. One-year mortality probability according to markers of iron deficiency and level of inflammation. Each panel indicates the relationship between hepcidin (a) and sTfR/log(ferritin) (b) at discharge and mortality probability according to the tertile of IL- 6 at discharge. The blue arrows indicate the threshold values for iron deficiency diagnosis. This figure shows that the relationship between ID (defined as either low hepdidin or high sTfR/log(ferritin) ratio) persists with different level of inflammation. It also suggests that different threshold may be proposed in the presence of inflammation. sTfR, soluble transferrin receptor; IL-6, interleukin-6. (DOCX $55 \mathrm{~kb}$ )

\section{Abbreviations}

Cl: Confidence interval; ELISA: Enzyme-linked immunosorbent assay Hb: Haemoglobin; ICU: Intensive care unit; ID: Iron deficiency; IL : Interleukin; OR: Odds ratio; QOL: Quality of life; SF-36: Short Form 36; sTfR: Soluble transferrin receptor

\section{Acknowledgements}

This study is based on the FROG-ICU cohort, for which all the FROG-ICU investigators recruited the patients. We thank them very much for this work. FROG-ICU study group:

Hopital Lariboisiere, Paris, France: N Deye, C Fauvaux, A Mebazaa, C Damoisel, D Payen.

Hopital Saint Louis, Paris, France: E Azoulay, AS Moreau, L Jacob, O Marie. Hopital Bichat, Paris, France: M Wolf, R Sonneville, R Bronchard.

Hopital Beaujon, Paris, France: I Rennuit, C Paugam.

Hopital, Cochin, Paris, France: JP Mira, A Cariou, A Tesnieres.

Hopital Bicetre, Paris, France: N Dufour, N Anguel, L Guerin, J Duranteau, C Ract. CHU de Marseille, Marseille, France: M Leone, B Pastene.

Hopital Raymond Poincarré, Garches, France: T Sharshar, A Fayssoyl. Hopital Saint-Antoine, Paris, France: J-L Baudel, B Guidet.

Hopital Pitié salpétrière, Paris, France: Q Lu, W Jie Gu, N Brechot, A Combes. CHU Saint Eloi, Montpellier, France: S Jaber, A Pradel, Y Coisel, M Conseil. Hopital Ambroise Paré, Boulogne Billancourt, France: A Veillard Baron, L Bodson. CHU Caremeau, Nimes, France: Jy Lefrant, L Elotmani, A Ayral, S Lloret. Hopital Hopital Jean Minjoz, Besançon, France: S Pily-Flouri, Jb Pretalli. Clinique Saint Luc, Louvain, Belgique: Pf Laterre, V Montiel, Mf Dujardin, C Berghe.

\section{Funding}

PHRC (AON 10-216) from the French ministry of health and Société Française d'Anesthésie-Réanimation. The Laboratory of excellence, GR-Ex, Paris, France supported this study. The labex GR-Ex, reference ANR-11-LABX0051 is funded by the programme "Investissements d'avenir" of the French National Research Agency, reference ANR-11-IDEX-0005-02. The funders of the study had no role in the study design; data collection, analysis, or interpretation; writing of the report; or decision to submit for publication.

\section{Availability of data and materials}

The corresponding author (SL), AM and EG had full access to all the study data. SL takes responsibility for the integrity of the data and the accuracy of the data analysis.

\section{Authors' contributions}

SL, AM and EG designed the study. TL and HP performed the hepcidin dosage. AM and EG designed and conducted the FROG-ICU study and recruited the patients. EG did the statistical analysis and prepared the figures. $S L, T L, C M, H P, A M$ and EG did the data analysis. SL wrote the first and final draft of the manuscript. All authors revised the report and read and approved the final version before submission.

\section{Ethics approval and consent to participate}

This study used data obtained from a previously published study, the FROGICU study [18, 19], conducted in France and Belgium in accordance with Good Clinical Practice (Declaration of Helsinki 2002) and Ethical Committee approvals (Comité de Protection des Personnes-lle de France IV, IRB n 00003835 and Commission d'éthique biomédicale hospitalo-facultaire de I'hôpital de Louvain, IRB nB403201213352).

\section{Consent for publication}

Not applicable.

\section{Competing interests}

Sigismond Lasocki has received speaker honoraria from VIFOR Pharma, MASIMO, LFB and fees as a member of the advisory board and/or Steering Committee from VIFOR Pharma and Pfizer. AM received speaker's honoraria from Abbott, Novartis, Orion, Roche and Servier, and fees as a member of the advisory board and/or Steering Committee from Cardiorentis, Adrenomed, MyCartis, Neurotronik and Sphyngotec. EG received a research grant from Sphingotec, and consultancy fees from Magnisense and Roche Diagnostics. The remaining authors declare that they have no competing interests.

\section{Publisher's Note}

Springer Nature remains neutral with regard to jurisdictional claims in published maps and institutional affiliations.

\section{Author details}

'Département Anesthésie Réanimation, UBL Université, CHU Angers, 4 rue Larrey, 49933 Angers Cedex 9, France. ${ }^{2}$ INSERM, UMR 1149/ERL CNRS 8252, Centre de Recherches sur l'inflammation, Université Paris Diderot, Paris, France. 'ªboratoire d'excellence du Globule Rouge GR-Ex ; APHP, Hôpital Universitaire Louis Mourier, Colombes, France. ${ }^{4}$ Department of Anesthesia, Université Paris Diderot ; U 942 Inserm ; APHP, Burn and Critical care, Hôpitaux Universitaires Saint louis - Lariboisiere, Paris, France.

Received: 16 August 2018 Accepted: 1 November 2018 Published online: 21 November 2018

\section{References}

1. Disease GBD, Injury I, Prevalence C. Global, regional, and national incidence, prevalence, and years lived with disability for 310 diseases and injuries, 1990-2015: a systematic analysis for the Global Burden of Disease Study 2015. Lancet. 2016;388(10053):1545-602

2. Zimmermann MB, Hurrell RF. Nutritional iron deficiency. Lancet. 2007; 370(9586):511-20.

3. Haas JD, Brownlie T. Iron deficiency and reduced work capacity: a critical review of the research to determine a causal relationship. J Nutr. 2001; 131(2S-2):676S-88S discussion 688S-690S.

4. Jankowska EA, Rozentryt P, Witkowska A, Nowak J, Hartmann O, Ponikowska B, Borodulin-Nadzieja L, Banasiak W, Polonski L, Filippatos G, et al. Iron 
deficiency: an ominous sign in patients with systolic chronic heart failure. Eur Heart J. 2010;31(15):1872-80.

5. Klip IT, Comin-Colet J, Voors AA, Ponikowski P, Enjuanes C, Banasiak W, Lok DJ, Rosentryt $\mathrm{P}$, Torrens A, Polonski L, et al. Iron deficiency in chronic heart failure: an international pooled analysis. Am Heart J. 2013;165(4):575-82 e573.

6. Fernandez R, Tubau I, Masip J, Munoz L, Roig I, Artigas A. Low reticulocyte hemoglobin content is associated with a higher blood transfusion rate in critically ill patients: a cohort study. Anesthesiology. 2010;112(5):1211-5.

7. Pieracci FM, Barie PS. Diagnosis and management of iron-related anemias in critical illness. Crit Care Med. 2006;34(7):1898-905.

8. Bellamy MC, Gedney JA. Unrecognised iron deficiency in critical illness. Lancet. 1998;352(9144):1903.

9. Lyon AW, Chin AC, Slotsve GA, Lyon ME. Simulation of repetitive diagnostic blood loss and onset of iatrogenic anemia in critical care patients with a mathematical model. Comput Biol Med. 2013;43(2):84-90.

10. von Ahsen N, Muller C, Serke S, Frei U, Eckardt KU. Important role of nondiagnostic blood loss and blunted erythropoietic response in the anemia of medical intensive care patients. Crit Care Med. 1999;27(12):2630-9.

11. Lasocki $S$, Longrois $D$, Montravers $P$, Beaumont $C$. Hepcidin and anemia of the critically ill patient. Anesthesiology. 2011;114(3):688-94.

12. Lasocki S, Chudeau N, Papet T, Tartiere D, Roquilly A, Carlier L, Mimoz O, Seguin $P$, Malledant $Y$, Asehnoune $K$, et al. Prevalence of iron deficiency on ICU discharge and its relation with fatigue: a multicenter prospective study. Crit Care. 2014;18(5):542.

13. Piagnerelli $M$, Vincent JL. Role of iron in anaemic critically ill patients: it's time to investigate! Crit Care. 2004;8(5):306-7.

14. Thomas DW, Hinchliffe RF, Briggs C, Macdougall IC, Littlewood T, Cavill I, British Committee for Standards in $\mathrm{H}$. Guideline for the laboratory diagnosis of functional iron deficiency. Br J Haematol. 2013;161(5):639-48.

15. Thomas C, Thomas L. Biochemical markers and hematologic indices in the diagnosis of functional iron deficiency. Clin Chem. 2002;48(7):1066-76.

16. Ganz T. Systemic iron homeostasis. Physiol Rev. 2013;93(4):1721-41.

17. Lasocki S, Baron G, Driss F, Westerman M, Puy H, Boutron I, Beaumont C, Montravers P. Diagnostic accuracy of serum hepcidin for iron deficiency in critically ill patients with anemia. Intensive Care Med. 2010;36(6):1044-8.

18. Gayat E, Cariou A, Deye N, Vieillard-Baron A, Jaber S, Damoisel C, Lu Q, Monnet X, Rennuit I, Azoulay E, et al. Determinants of long-term outcome in ICU survivors: results from the FROG-ICU study. Crit Care. 2018;22(1):8.

19. Mebazaa A, Casadio MC, Azoulay E, Guidet B, Jaber S, Levy B, Payen D, Vicaut E, Resche-Rigon M, Gayat E. Post-ICU discharge and outcome: rationale and methods of the The French and euRopean Outcome reGistry in Intensive Care Units (FROG-ICU) observational study. BMC Anesthesiol. 2015:15:143.

20. Lefebvre T, Dessendier N, Houamel D, laly-Radio N, Kannengiesser C, Manceau H, Beaumont C, Nicolas G, Gouya L, Puy H, et al. LC-MS/MS method for hepcidin-25 measurement in human and mouse serum: clinical and research implications in iron disorders. Clin Chem Lab Med. 2015;53(10): 1557-67.

21. Stevens GA, Finucane MM, De-Regil LM, Paciorek CJ, Flaxman SR, Branca F, Pena-Rosas JP, Bhutta ZA, Ezzati M, Nutrition Impact Model Study G. Global, regional, and national trends in haemoglobin concentration and prevalence of total and severe anaemia in children and pregnant and non-pregnant women for 1995-2011: a systematic analysis of population-representative data. Lancet Glob Health. 2013;1(1):e16-25.

22. Camaschella C. Iron deficiency: new insights into diagnosis and treatment. Hematology Am Soc Hematol Educ Program. 2015;2015:8-13.

23. Munoz M, Laso-Morales MJ, Gomez-Ramirez S, Cadellas M, Nunez-Matas MJ, Garcia-Erce JA. Pre-operative haemoglobin levels and iron status in a large multicentre cohort of patients undergoing major elective surgery. Anaesthesia. 2017:72(7):826-34

24. Cohen-Solal A, Leclercq C, Deray G, Lasocki S, Zambrowski JJ, Mebazaa A, de Groote P, Damy T, Galinier M. Iron deficiency: an emerging therapeutic target in heart failure. Heart. 2014;100(18):1414-20.

25. Pieracci FM, Henderson P, Rodney JR, Holena DN, Genisca A, Ip I, Benkert S, Hydo L, Eachempati SR, Shou J, et al. Randomized, double-blind, placebocontrolled trial of effects of enteral iron supplementation on anemia and risk of infection during surgical critical illness. Surg Infect. 2009;10(1):9-19.

26. Munoz M, Romero A, Morales M, Campos A, Garcia-Erce JA, Ramirez G. Iron metabolism, inflammation and anemia in critically ill patients. A crosssectional study. Nutr Hosp. 2005;20(2):115-20.
27. Rodriguez RM, Corwin HL, Gettinger A, Corwin MJ, Gubler D, Pearl RG Nutritional deficiencies and blunted erythropoietin response as causes of the anemia of critical illness. J Crit Care. 2001;16(1):36-41.

28. van der Vorm LN, Hendriks JC, Laarakkers $C M$, Klaver $S$, Armitage $A E_{\text {, }}$ Bamberg A, Geurts-Moespot AJ, Girelli D, Herkert M, Itkonen O, et al. Toward worldwide hepcidin assay harmonization: identification of a commutable secondary reference material. Clin Chem. 2016;62(7):993-1001.

29. Cherry-Bukowiec JR, Engoren M, Wiktor A, Raghavendran K, Napolitano LM. Hepcidin and anemia in surgical critical care: a prospective cohort study. Crit Care Med. 2018;46(6):e567-74.

30. Lasocki S, Millot S, Andrieu V, Letteron P, Pilard N, Muzeau F, Thibaudeau O, Montravers $P$, Beaumont C. Phlebotomies or erythropoietin injections allow mobilization of iron stores in a mouse model mimicking intensive care anemia. Crit Care Med. 2008;36(8):2388-94.

31. Rineau E, Gaillard T, Gueguen N, Procaccio V, Henrion D, Prunier F, Lasocki S Iron deficiency without anemia is responsible for decreased left ventricular function and reduced mitochondrial complex I activity in a mouse model. Int J Cardiol. 2018:266:206-12.

32. Patterson AJ, Brown WJ, Powers JR, Roberts DC. Iron deficiency, general health and fatigue: results from the Australian Longitudinal Study on Women's Health. Qual Life Res. 2000;9(5):491-7.

33. Jankowska EA, Tkaczyszyn M, Suchocki T, Drozd M, von Haehling S, Doehner W, Banasiak W, Filippatos G, Anker SD, Ponikowski P. Effects of intravenous iron therapy in iron-deficient patients with systolic heart failure: a metaanalysis of randomized controlled trials. Eur J Heart Fail. 2016;18(7):786-95.

34. Krayenbuehl PA, Battegay E, Breymann C, Furrer J, Schulthess G. Intravenous iron for the treatment of fatigue in nonanemic, premenopausal women with low serum ferritin concentration. Blood. 2011;118(12):3222-7.

35. Heming N, Letteron P, Driss F, Millot S, El Benna J, Tourret J, Denamur E, Montravers $\mathrm{P}$, Beaumont $\mathrm{C}$, Lasocki S. Efficacy and toxicity of intravenous iron in a mouse model of critical care anemia. Crit Care Med. 2012;40(7): 2141-8.

36. Lasocki S, Piednoir P, Couffignal C, Rineau E, Dufour G, Lefebvre T, Puy H, Duval $X$, Driss F, Schilte C. Does IV iron induce plasma oxidative stress in critically ill patients? A comparison with healthy volunteers. Crit Care Med. 2016:44(3):521-30

37. Investigators I, Litton E, Baker S, Erber WN, Farmer S, Ferrier J, French C, Gummer J, Hawkins D, Higgins A, et al. Intravenous iron or placebo for anaemia in intensive care: the IRONMAN multicentre randomized blinded trial: a randomized trial of IV iron in critical illness. Intensive Care Med. 2016; 42(11):1715-22.

38. Lasocki S, Puy H, Mercier G, Lehmann S, Hepcidane study g. Impact of iron deficiency diagnosis using hepcidin mass spectrometry dosage methods on hospital stay and costs after a prolonged ICU stay: study protocol for a multicentre, randomised, single-blinded medico-economic trial. Anaesth Crit Care Pain Med. 2017;36(6):391-6.

\section{Ready to submit your research? Choose BMC and benefit from:}

- fast, convenient online submission

- thorough peer review by experienced researchers in your field

- rapid publication on acceptance

- support for research data, including large and complex data types

- gold Open Access which fosters wider collaboration and increased citations

- maximum visibility for your research: over 100M website views per year

At BMC, research is always in progress.

Learn more biomedcentral.com/submissions 